Section Editor Mitchell S.V. Elkind, MD, MS

Sunil A. Mutgi, MD

Alicia M. Zha, MD

Reza Behrouz, DO

Correspondence to

Dr. Mutgi:

sunil.mutgi@osumc.edu
Supplemental data at Neurology.org

\title{
Emerging Subspecialties in Neurology: Telestroke and teleneurology
}

(6)

In 2013, Dall et al. ${ }^{1}$ projected that by 2025 , the societal need for neurologists will exceed availability by $19 \%$. This number failed to account for the disproportionate number of neurologists practicing in urban and academic centers, likely underestimating the gap in rural populations. In a recent effort to improve access to neurologic services in these areas, telestroke and teleneurology networks have being championed as the solution. With the emergence of these networks come unique challenges and opportunities in the distribution and breadth of neurologic care that fellows and residents will need to understand to optimally incorporate this tool into their future practices.

History and development. Telemedicine was first conceptualized in 1924 in Radio News Magazine, where the idea of a future including "video-radio" for medical diagnosis and management was introduced. ${ }^{2}$ The American Telemedicine Association formally defines the term to mean the use of medical information exchanged from one site to another via electronic communications to improve a patient's clinical health status. This concept continues to undergo extensive metamorphosis as technology has evolved and as implementation within multiple medical subspecialties has grown. In neurology, 2 terms are now used in general practice: teleneurology, the application of telemedicine to the field of neurology; and telestroke, a subdivision of teleneurology involving telemedicine consultation for the treatment of neurovascular patients. Both definitions are conventionally accepted within the field and are recognized to include the use of high-quality audiovideo conferencing with or without the inclusion of electronic medical records, radiographic imaging, or other physiologic data. ${ }^{3-5}$

Initial rudimentary implementations of telemedicine consisted only of remote telephone consultations between physicians. In time, this tool has come to encompass remote audio-video consultations and electronic transmission of radiographic imaging with or without physiologic data and electronic medical records. ${ }^{5}$ Regrettably, for many years, barriers to implementation existed that limited application of telemedicine systems to grant-funded tertiary academic centers and widespread acceptance of telemedicine was nonexistent. ${ }^{3,5,6}$ Initially, these barriers appeared insurmountable—video systems were bulky, software was insecure, high-speed network access was scarce, physical examinations were not standardized, credentialing responsibilities were unclear, and reimbursement for services was undefined. ${ }^{3-6}$ Despite these and other barriers to widespread implementation, the tide did eventually turn following the results of the National Institute of Neurological Disorders and Stroke recombinant tissue plasminogen activator (rtPA) trial in 1996. With a Food and Drug Administration-approved time-sensitive treatment for stroke, the question of improving time to administration was forefront. In 1999, Levine and Gorman ${ }^{3}$ provided the answer, in their landmark article "Telestroke': the application of telemedicine for stroke," in which they demonstrated that rtPA could be safely administered remotely by telemedicine.

With physicians finally able to justify the high cost of advanced telemedicine implementation and utilization, telestroke progressively became more widespread and other barriers slowly began to dissolve. To improve diagnostic accuracy, remote physical examination of suspected stroke patients has become standardized. The NIH Stroke Scale (NIHSS), now a well-established and validated assessment, was developed and implemented. ${ }^{7}$ Technology has continued to evolve under pressure for more portable communication systems and telemedicine consultations can now be provided from anywhere if a laptop and high-speed Internet access are available. Billing and licensure concerns, while still valid, are being actively addressed at federal and local levels. Centers for Medicare and Medicaid Services have published rules allowing reciprocity of physician privileging and Medicare has improved reimbursement for telestroke consultation with implementation of DiagnosticRelated Group 559.4,5

With the implementation of telestroke spreading rapidly in the United States, a prevailing model has emerged and is becoming the gold standard. This model, known as the hub and spoke model, is centered on the understanding that large tertiary medical

From the Department of Neurology, Wexner Medical Center, The Ohio State University, Columbus.

Go to Neurology.org for full disclosures. Funding information and disclosures deemed relevant by the authors, if any, are provided at the end of the article. 
centers, known as hub hospitals, have access to resources not available to smaller spoke hospitals, making telestroke consultation mutually financially beneficial. ${ }^{4,8}$ In this model, the tertiary medical center has a rotating call schedule with a large group of trained vascular neurologists to respond to the telestroke consultations. ${ }^{4,8}$ This provides spoke hospitals continuous access to specialty evaluation for acute stroke patients. ${ }^{4,8}$ In 2013, Switzer et al. ${ }^{8}$ reported a cost-benefit analysis of this model, which validated that a mutual financial benefit does exist, but only when a skilled specialist is able to differentiate the patients best indicated for hospital transfer. In another analysis of the evolving hub-spoke system, Silva et al. ${ }^{4}$ conducted a survey in 2012 of multiple telestroke network sites and concluded that telestroke is a "widespread and growing practice model," but that variations of the models exist. In their review, they noted that a percentage of hub systems reported utilizing contract neurologists as a component of their vascular neurology pool and that nearly $50 \%$ of the reviewed programs incorporated isolated telephone consultations into their telestroke model. ${ }^{4}$ In all variations reviewed, it was apparent that a wellimplemented hub and spoke model is an effective method of implementing telestroke. ${ }^{4}$

With the success of telestroke, recent focus has turned to applications in general neurology. Between 2013 and 2014, 2 of the most comprehensive teleneurology assessments to date were published, creating thought-provoking considerations for future implementation of teleneurology. The study by Davis et al. ${ }^{9}$ evaluated 354 patients treated under the Veterans Health Administration. All patients in the study underwent initial on-site clinical evaluation and appropriate ancillary testing followed by off-site teleneurology follow-up. The authors determined that clinical management and patient satisfaction were not affected by this model of outpatient teleneurology assessment. ${ }^{9}$ The second study was a review completed by Wechsler et al. ${ }^{7}$ as part of an American Academy of Neurology (AAN)-established Telemedicine Work Group. As this was not a clinical trial, they were only able to suggest potential impediments and advantages to teleneurology implementation. Most barriers noted were similar to those previously seen with telestroke network development. A new consideration in the outpatient setting was the doctor-patient relationship; however, this has been addressed in the simultaneous Davis et al. ${ }^{9}$ study. The workgroup did raise multiple potential benefits to more generalized teleneurology implementation in addition to those previously recognized in telestroke networks. Reduced travel time, reduced cost for patients, and improved access to care for immobilized patients were considered significant potential benefits by the AAN group, and these benefits were seen in the study by Davis et al. ${ }^{9}$ as well as in subsequent published reviews. ${ }^{7,10}$ Additionally, the AAN group suggested potential benefits of improved clinical trial recruitment, and utilization of teleneurology for enhanced resident-fellow education, yet unrealized benefits of teleneurology. ${ }^{7}$

How to prepare our residents and fellows for the future. Neurology is evolving to incorporate telemedicine into daily practice. The success or failure of this integration will depend on the skills endowed upon our rising residents and fellows. The current training for remote management of neurologic conditions utilizing telemedicine systems is limited outside of select neurovascular fellowship programs. Dependent on the abilities of a remote site, examinations can be facilitated either by utilizing standardized assessment scales such as the NIHSS or through instruction of a certified nurse who can remotely complete a detailed neurologic assessment, acting as an extension of the examiner. Development of the skills required to remotely interpret these complex neurologic examinations requires experience, best initially obtained under supervision.

As teleneurology continues to be incorporated into practice, it will need to also be integrated to a greater degree into the daily lives of trainees. Figure e-1 on the Neurology ${ }^{\circledR}$ Web site at Neurology.org notes general applications for inpatient and outpatient teleneurology. On the inpatient side, an expansion of consult services will likely occur to encompass the additional consultations generated from local hospitals through teleneurology, while transferred patients will continue to be integrated into existing hospital inpatient services. For outpatient services, the neurology community will likely begin to see follow-up of appropriately chosen patients in rural communities through teleneurology satellite clinics, easing the typical patient burdens associated with the cost of transportation to tertiary care centers. With multiuser teleneurology software available after establishment of a primary network, trainees will be able to be integrated into this process, taking the role of primary physician under the physical or electronic guidance of a licensed attending physician.

After sufficient supervised training, the fellows and residents can be introduced to higher levels of independence utilizing the teleneurology system congruent with their individual level of training. Fellows will likely become more independently involved with spoke hospital assessments both in teleneurology and telestroke and residents would be able to conduct limited teleneurology assessments in place of traditional phone assessments for patient questions or concerns. By such integrations, rising residents and fellows will 
develop the necessary skills to optimize the benefits of teleneurology as we move into a future of possibility while educating them to provide fiscally responsible care and improving patient access to neurologic specialists.

\section{AUTHOR CONTRIBUTIONS}

Sunil A. Mutgi: initial conception of manuscript direction, evaluation of the literature, and completion of final manuscript through multiple revisions. Alicia M. Zha: direct participation in the structuring, revision, and production of the final manuscript. Reza Behrouz: primary attending/ mentoring physician, direct participation in structuring the manuscript, review of multiple drafts and revisions, providing instruction for revisions, and approval of final manuscript.

\section{STUDY FUNDING}

No targeted funding reported.

\section{DISCLOSURE}

The authors report no disclosures relevant to the manuscript. Go to Neurology.org for full disclosures.

\section{REFERENCES}

1. Dall TM, Storm MV, Chakrabarti R, et al. Supply and demand analysis of the current and future US neurology workforce. Neurol 2013;81:470-478.

2. Field MJ; Institute of Medicine (US) Committee on Evaluating Clinical Applications of Telemedicine. Evolution and Current Applications of Telemedicine. Available at:
http://www.ncbi.nlm.nih.gov/books/NBK45445/. Accessed July 17, 2014.

3. Levine SR, Gorman M. "Telestroke": the application of telemedicine for stroke. Stroke 1999;30:464-469.

4. Silva GS, Farrell S, Shandra E, Viswanathan A, Schwamm LH. The status of telestroke in the United States a survey of currently active stroke telemedicine programs. Stroke 2012;43:2078-2085.

5. Switzer JA, Levine SR, Hess DC. Telestroke 10 telestroke years later: telestroke 2.0. Cerebrovasc Dis 2009;28: 323-330.

6. Teleneurology: beyond stroke care. Telemed J E Health 2010;16:772-775.

7. Wechsler LR, Tsao JW, Levine SR, et al. Teleneurology applications: report of the Telemedicine Work Group of the American Academy of Neurology. Neurol 2013;80: 670-676.

8. Switzer JA, Demaerschalk BM, Xie J, Fan L, Villa KF, Wu EQ. Cost-effectiveness of hub-and-telestroke spoke telestroke networks for the management of acute ischemic stroke from the hospitals' perspectives. Circ Cardiovasc Qual Outcomes 2013;6:18-26.

9. Davis LE, Coleman J, Harnar J, King MK. Teleneurology: successful delivery of chronic neurologic care to 354 patients living remotely in a rural state. Telemed J E Health 2014;20:473-477.

10. Timpano F, Bonanno L, Bramanti A, et al. Tele-health and neurology: what is possible? Neurol Sci 2013;34: 2263-2270. 


\section{Neurology}

\section{Emerging Subspecialties in Neurology: Telestroke and teleneurology \\ Sunil A. Mutgi, Alicia M. Zha and Reza Behrouz \\ Neurology 2015;84;e191-e193 \\ DOI 10.1212/WNL.0000000000001634}

\section{This information is current as of June 1, 2015}

\section{Updated Information \& Services \\ Supplementary Material}

References

Citations

Subspecialty Collections

Permissions \& Licensing

Reprints including high resolution figures, can be found at: http://n.neurology.org/content/84/22/e191.full

Supplementary material can be found at: http://n.neurology.org/content/suppl/2015/05/30/WNL.0000000000001 634.DC1

http://n.neurology.org/content/suppl/2015/05/30/WNL.0000000000001 634.DC2

This article cites 9 articles, 5 of which you can access for free at: http://n.neurology.org/content/84/22/e191.full\#ref-list-1

This article has been cited by 3 HighWire-hosted articles: http://n.neurology.org/content/84/22/e191.full\#\#otherarticles

This article, along with others on similar topics, appears in the following collection(s):

All Cerebrovascular disease/Stroke

http://n.neurology.org/cgi/collection/all_cerebrovascular_disease_strok

\section{All Clinical Neurology}

http://n.neurology.org/cgi/collection/all_clinical_neurology

Information about reproducing this article in parts (figures,tables) or in its entirety can be found online at:

http://www.neurology.org/about/about_the_journal\#permissions

Information about ordering reprints can be found online:

http://n.neurology.org/subscribers/advertise

Neurology ${ }^{\circledR}$ is the official journal of the American Academy of Neurology. Published continuously since 1951 , it is now a weekly with 48 issues per year. Copyright @ 2015 American Academy of Neurology. All rights reserved. Print ISSN: 0028-3878. Online ISSN: 1526-632X.

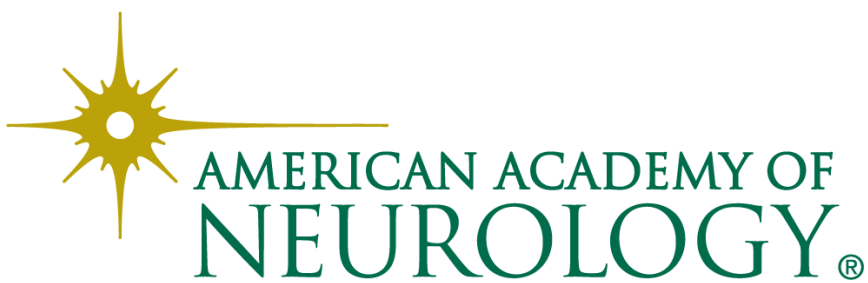

